\title{
Mass Imprisonment and the Extended Family
}

\author{
Pil H. Chung, Peter Hepburn
}

University of California, Berkeley

Abstract: This study employs microsimulation techniques to provide an accounting of exposure to imprisoned or formerly imprisoned kin. We characterize the risk and prevalence of imprisonment within full kinship networks and find that the life course trajectories of familial imprisonment experienced by black and white Americans take on qualitatively distinct forms: the average black American born at the height of the prison boom experienced the imprisonment of a relative for the first time at age 7 and by age 65 belongs to a family in which more than 1 in 7 working-age relatives have ever been imprisoned. By contrast, the average white American who experiences the imprisonment of a relative does not do so until age 39 and by age 65 belongs to a family in which 1 in 20 working-age relatives have ever been imprisoned. Future reductions in imprisonment rates have the potential to meaningfully reduce these racial disparities in family imprisonment burden.

Keywords: prison; family; race; microsimulation

TWO bodies of research have been particularly important in tracing the full reach

1 of the carceral state into the American family during the era of mass imprisonment. The first uses formal demographic methods to document variations, by cohort, race, and education, in the cumulative risk of own and paternal imprisonment (Bonczar 2003; Bonczar and Beck 1997; Pettit and Western 2004; Western and Wildeman 2009; Wildeman 2009). The second explores the "connectedness" of prisoners to friends, family, and local communities (Clear 2007; Lee et al. 2015; Rose and Clear 2004; Wildeman and Turney 2014). Taken together, these bodies of research offer substantial insight into how individuals and families have been touched-directly or indirectly - by the rise in imprisonment rates since the early 1970s.

One element that is missing from these literatures, however, is an analysis of how the prison boom has affected extended family networks and the exposure to imprisonment within such networks. Demographic research provides estimates of an individual's risk of own or paternal imprisonment but not similar estimates detailing, for example, cousin's or uncle's imprisonment or-more importantly-the overall number of family members likely to ever be imprisoned. The connectedness literature, by contrast, does in some cases extend beyond the nuclear family, but as is discussed below, data limitations curtail analyses of change over time and of connectedness to previously incarcerated individuals.

In this study, we combine the methodological innovation of the demographic work on cumulative imprisonment risk with the research imperative of the connectedness literature. Building on life table approaches, we employ a microsimulation technique to infer lifetime trajectories of imprisonment from cross-sectional counts and rates. ${ }^{1}$ This allows us to account for changes in the magnitude of imprisonment risk over historical time and in the distribution of that risk over ages and across 
races. Simply applied to individuals or parent-child dyads, these simulations would tell us little that previous demographic research has not. Indeed, we exploit this overlap: we replicate previous research findings as a check on the plausibility of the assumptions that underlie our models (see Appendix A3 of the online supplement). Our major contribution is to go one step further and to estimate imprisonment risks within entire kinship networks for multiple cohorts of black and white Americans.

Our findings indicate that the risk of imprisonment within extended kin networks has fallen earlier and more heavily upon black Americans than on white Americans: the average black American born at the height of the prison boom experienced the imprisonment of a relative for the first time at age 7 and by age 65 is expected to belong to a family in which more than 1 in 7 working-age relatives have ever been imprisoned. By contrast, the average white American who experiences the imprisonment of a relative does not do so until age 39 and by age 65 is expected to belong to a family in which 1 in 20 working-age relatives have ever been imprisoned. Parents, partners, and children-the relations typically studied in research on the collateral consequences of imprisonment-constitute less than half of the overall exposure to imprisonment within kinship networks. We leverage the capacity of simulations to look toward the future, evaluating the potential effects of several proposed decarceration goals. We find that national reductions in imprisonment rates could eventually lead to a meaningful narrowing of the race gap in kin imprisonment, but these reductions-even if implemented immediately-would not dramatically change the lifetime prevalence of kin imprisonment for those families whose members have already lived through the prison boom.

\section{Background}

Imprisonment curtails the benefits that arise from social networks in which currently and formerly imprisoned individuals are embedded (Comfort 2007). These collateral consequences have been theorized and demonstrated in several domains. Neighborhoods suffer declines in informal social control and collective efficacy as the proportion of residents who are current or former prisoners increases (Lynch and Sabol 2004). Schools are affected: even children without incarcerated parents fare worse academically as a school's proportion of incarcerated parents increases (Hagan and Foster 2012).

The extended family is a similar meso-level institution within which increased exposure to imprisonment yields poorer outcomes for its members. Higher rates of imprisonment within a kin network curtail available resources because (1) family members-including extended kin-pay significant immediate and long-term costs and (2) former prisoners are less able to contribute to kin support. The combination of these two factors can lead to the weakening of ties within the network (Braman 2004). Before detailing these costs entailed by kin imprisonment, we briefly describe racial variations in kin contact and support. 


\section{Race Differences in Kin Contact and Support}

Not all kin networks are likely to be equally affected by the imprisonment of a member. Looser, more disconnected families may feel few effects; tightly knit families engaged in regular contact and mutual support may feel effects more strongly. If there are no racial differences in the likelihood and magnitude of kin contact and support, then in aggregate, the effects of kin imprisonment should be felt equally across black and white families. If, however, one group displays consistently higher levels of contact and support, then that group may be particularly hard hit by the effects of kin imprisonment.

Available evidence supports the latter premise. Research suggests that black Americans are far more likely to coreside with a family member than white Americans (Keene and Batson 2010). Compared to white individuals, black individuals live in closer physical proximity to their kin, have more kin available locally, and have more frequent contact with those family members (Ajrouch, Antonucci, and Janevic 2001; Taylor et al. 2013). Findings on the exchange of support within black and white families are mixed. A number of studies find that white individuals are more likely to exchange financial assistance with family members, though much research in this vein is limited to the parent-child dyad (Jayakody 1998; Lee and Aytac 1998). By contrast, black individuals appear more likely than their white counterparts to give and receive emotional support and childcare and to do care work generally (Sarkisian and Gerstel 2004). Notably, several studies document the regularity with which black individuals incorporate extended kin into such exchange patterns (Johnson and Barer 1995; Raley 1995).

\section{Costs of Kin Imprisonment}

These findings suggest that black families are often organized in ways that would exacerbate the spillover effects of kin imprisonment. What, though, are these consequences, and are they felt by extended kin? Most attention has been paid to the effects on prisoners' immediate family members: children (Murray and Farrington 2008; Wakefield and Wildeman 2014), partners (Wildeman, Schnittker, and Turney 2012), and mothers (Braman 2004; Turney 2014). ${ }^{2}$ Little quantitative research has examined the effects of kin imprisonment beyond these close ties. ${ }^{3}$ This is, to some extent, unsurprising: the major data sources leveraged in this field-the Fragile Families and Child Wellbeing Study and the National Longitudinal Study of Adolescent Health-do not include sufficient information on networks and imprisonment of distal relatives to support analysis. There is, however, reason to believe that imprisonment does affect extended kin in at least two ways: by imposing costs on families and by reducing current and former prisoners' contributions to kin support.

Many of the costs of imprisonment are either borne directly by or indirectly affect nonimmediate family members. These start with the significant expenses of maintaining contact with and materially supporting an imprisoned family member (DeVuono-Powell et al. 2015). Family members regularly pay for childcare or directly house and care for the children of prisoners (Green et al. 2006). The material hardship and stress of kin imprisonment results in a range of health 
problems (Lee et al. 2014), and stigma leads family members to withdraw from social relationships, reducing their access to interpersonal support and exacerbating depressive symptoms (Braman 2004).

Costs extend beyond the period of imprisonment. Most prison inmates hold legal financial obligations that result from their conviction (Harris, Evans, and Beckett 2010). The majority of formerly imprisoned individuals report that family members-including extended kin-are their primary support in paying off these debts (Nagrecha, Katzenstein, and Davis 2015). Former prisoners are also heavily reliant on family members for other financial assistance, housing, emotional support, food, and transportation (Harding et al. 2014).

Kin networks also suffer due to long-term reductions in prisoners' ability to support themselves and others. Former prisoners have worse employment options and outcomes than their never-imprisoned peers (Uggen, Manza, and Thompson 2006) and suffer a range of long-term health problems (Massoglia 2008), which further inhibit their prospects and represent an additional strain on family members. Furthermore, imprisonment lowers net worth and the odds of wealth accumulation (Turney and Schneider 2016), and many ex-prisoners are permanently ineligible for a range of social welfare benefits (DeVuono-Powell et al. 2015). As a result, former prisoners contribute less financially to their children (Geller, Garfinkel, and Western 2011), and the immediate families of prisoners face higher levels of material hardship (Schwartz-Soicher, Geller, and Garfinkel 2011).

This suggests that (1) family members face considerable financial and emotional costs due to kin imprisonment and (2) that currently and previously imprisoned individuals will be less able to reciprocate the support they receive from kin. Thus, former prisoners represent a unique sort of negative social capital: a node in one's kin network that offers little social support (and no social leverage) (de Souza Briggs 1998) but that regularly makes demands ( $\mathrm{O}^{\prime}$ Brien 2012). The compounding effects of these two factors may lead to the fraying of family ties. Braman describes how the stigma of imprisonment and the breakdown of reciprocal exchange lead kin to withdraw from one another. As he puts it, "the relationships and norms described as social capital have increasingly become burdens rather than benefits to many inner-city families" (2004:7). The breakdown of kin networks due to these processes represents an additional—perhaps even more severe—cost of kin imprisonment.

\section{Imprisonment Risk and Connectedness to Prisoners}

Given the ways in which the burdens of imprisonment can diffuse into broader family networks and persist for years, it is important to assess how exposure to kin imprisonment is structured across the population and over the course of affected individuals' lives. Previous research has detailed variations, by cohort, race, and education, in the cumulative risk of own and paternal imprisonment (Pettit and Western 2004; Wildeman 2009). These studies employ formal demographic methods to convert period measures of current imprisonment into cohort measures of cumulative risk. What they do not provide-and indeed cannot provide given limitations in the data upon which they rely-is insight into how the prison boom has affected the exposure to imprisonment within extended family networks. 
The connectedness literature offers several examples of research aiming beyond the nuclear family. Lee et al. (2015) use the 2006 General Social Survey to estimate the probability of having a currently imprisoned family member (of any relation). Wildeman and Wakefield (2014) use data from the Project on Human Development in Chicago Neighborhoods to analyze the concentration of imprisonment within family networks, demonstrating that children of incarcerated parents are more likely to have other relatives simultaneously incarcerated. Both studies offer new insight into imprisonment within family networks, but the data used in both cases lead to notable limitations: neither study allows for any conclusions about changing rates of connectedness over time nor for identification of the previously imprisoned within family networks. Also, reliance on respondent recall of imprisonment and family network composition presents the risk of error due to selection and imperfect recollection. This concern is amplified by recent findings of underreporting of familial imprisonment and racial variations therein (Geller, Jaeger, and Pace 2016; Sykes and Pettit 2014).

In what follows, we describe a demographic microsimulation strategy that allows for the estimation of kin imprisonment over both historic and individual time and for a much wider set of kin relations than is feasible to produce by using any existing observational data.

\section{Methods}

This article provides estimates of imprisonment within extended kinship networks of black and white Americans over the course of the prison boom of the 1980s and 1990s. We consider the extended kinship network, which includes not only nuclear kin but all living relatives descended from a common grandparent (including grandparents, grandchildren, aunts, uncles, cousins, nieces, and nephews). To enable measurement of this expanded scope, we rely on data generated by a microsimulation technique that takes observed rate schedules in population fertility, mortality, and imprisonment as inputs and returns complete estimates of genealogical relatedness for all simulated individuals over their entire lifespans. In the sections that follow, we describe this simulation model, the data and assumptions upon which it is based, and the specific questions that we seek to answer with it.

\section{Data Limitations and Microsimulation}

The kinds of data that are necessary to explore kinship trends are difficult to find. Data sets that include information on family networks are rarely complete enough to encompass the full range of familial relations held by respondents throughout the course of their lives. Family data in the U.S. Census, for example, miss all kin relations not contained within household boundaries (e.g., adult siblings and independent children).

Although multiple waves of the Survey of Inmates in State and Federal Correctional Facilities (SISFCF) offer the possibility of addressing any number of important questions, their utility is limited when it comes to analyzing broader kin relations, kin availability over the life course, and certain population-level exposure rates. 
These surveys include information on prisoners' close kin relations (e.g,.parents, children, siblings, and significant others) but do not collect data on extended kin relations, such as grandparents, grandchildren, uncles/aunts, and cousins. The data that are collected on close kin are also time invariant, which forecloses analyses of changing kin composition over the life course. We are, at the time of this writing, unaware of any survey data that would allow us to directly measure the connectedness of prisoners to their extended kinship networks over the life course.

To overcome these data limitations, we employ a microsimulation framework to characterize the lifetime trajectories of kinship and imprisonment of non-Hispanic black and white U.S. populations over the course of the prison boom. ${ }^{4}$

In practice, we achieve this by utilizing SOCSIM, a well-validated microsimulation tool developed and maintained at the University of California, Berkeley, ${ }^{5}$ to simulate fictive groups of individuals calibrated to match the demographic behavior of black and white populations born between 1960 and 2010. Within SOCSIM, these simulated individuals "live" out their digital lives, partnering, creating offspring, becoming imprisoned, and dying within the parameters set by externally imposed rate schedules. At the conclusion of each simulation, SOCSIM returns a complete data set with the full demographic characteristics of each individual, including all the genealogical variables necessary to reconstruct that individual's entire kinship network (including the imprisonment status of the kin that make up those networks).

To facilitate comparisons between black and white experiences, we run two separate simulations: once with demographic and imprisonment rates for whites and a second time with the corresponding rates for blacks. Other than the different rate inputs, the two simulations are exactly identical in specification. To reduce variation due to the randomness of any single simulation, we run each race-specific simulation 25 times and average measurements, weighted by population size, across all runs. ${ }^{6}$

\section{The Microsimulation Model}

We configure our race-specific simulation models with four sets of data inputs: (1) age-specific fertility rates, (2) age- and sex-specific mortality rates, (3) age- and sex-specific prison admission rates, and (4) age- and sex-specific prison release rates. Fertility and mortality rate inputs for the period of 1960 to 2010 are derived from the U.S. National Vital Statistics System (NVSS) central fertility rate tables (Heuser 1976) and life tables (Arias 2014; Hamilton and Cosgrove 2010, 2012), respectively. Prison admission and release rate inputs over this same period, on the other hand, are more difficult to assign due to less consistent reporting of this information.

The Bureau of Justice Statistics (BJS) provides race-stratified annual counts of prison admissions for the years 1960, 1964, 1970, and then every year from 1974 to 2014 (Langan 1991; United States Bureau of Justice Statistics 2016a, 2016b) and annual counts of prison releases for every year from 1978 to 2014 (Carson and Golinelli 2013; United States Bureau of Justice Statistics 2016a, 2016b). Because these counts are reported at uneven intervals, we must choose a method by which we can "fill in" data for the gap years. Ultimately, we settle on linear interpolation as a 
reasonably conservative solution. Additionally, unlike the fertility and mortality information derived from the NVSS, counts of prison admissions and releases are not always reported separately by race, sex, and age. Because our SOCSIM models require inputs in this stratified form, we must choose a method by which we can distribute our counts of admissions and releases along the different race, sex, and age strata in our simulation model. The strategy we adopt, again, is to linearly interpolate the race, sex, and age distributions for gap years and apply these interpolated proportions when assigning counts to each of the unknown race, sex, and age strata. ${ }^{7}$ These admissions and release counts that have been thus harmonized with respect to their distribution across simulation years and across the different race, sex, and age strata form the numerators for the raw SOCSIM admission and release rate inputs. For the denominators, we rely on the U.S. Census Bureau's historical and intercensal estimates of national population counts (U.S. Census Bureau 2015) and the BJS's and University at Albany Sourcebook of Prison Statistics' national prison population counts (Carson and Sabol 2014; Langan 1991; University at Albany 2012) for calculating the admissions and release rates, respectively.

For the period extending beyond 2014, we simply hold our simulation rates fixed at the latest specified values (i.e., 2010 for fertility and mortality and 2014 for prison admission and release). For the supplementary analysis of future imprisonment rate trajectories (described below), we run three additional simulations that each modify the 2015 prison admission rates to simulate three potential futures: (1) a dramatic, 75 percent reduction in imprisonment; (2) a moderate, 25 percent reduction in imprisonment; and (3) no change in imprisonment.

Finally, to ensure that our simulations reliably reproduce observed population trends in each of our input domains, we employ a rigorous calibration procedure that multiplicatively scales each of the input rate parameters over each decade of simulation until the likelihood of reproducing known population-level measures in those variables (i.e., total fertility rate, life expectancy at birth, and rate of first admission to prison) is maximized in our data. ${ }^{8}$ Then, as a final check of our fully calibrated simulation model's ability to return plausible results, we compare measures of own and family imprisonment reported by three previous studies (Lee et al. 2015; Western and Wildeman 2009; Wildeman 2009) with those generated by our models. In brief, we find close agreement (within 3 percentage points) between our estimates of own and parental imprisonment risk with those reported by Western and Wildeman (2009) and Wildeman (2009). Similarly, we find reasonably close agreement between our estimates of current family imprisonment prevalence and those reported by Lee et al. (2015). ${ }^{9}$ The ability of our simulation model to largely replicate the results of these previous studies suggests that our methodological approach is, at least, no worse than the current standard.

\section{Outcomes of Interest}

Using the data from our simulation models, we calculate age-specific estimates of kin imprisonment: both the incidence and prevalence, within kinship networks, of relatives who have ever been imprisoned. For our purposes, we define "kin" as including 
all relatives descended from at least one common grandparent: grandparents (on both the father's and mother's side), parents, aunts/uncles (on both the father's and mother's side), siblings, and cousins (on both the father's and mother's side). We define "incidence" of kin imprisonment as the probability that a living relative is imprisoned (for the first time) over a particular year of ego's life; and we define "prevalence" of kin imprisonment as the proportion of living relatives who have ever been imprisoned by a particular year of ego's life. For our measures of incidence, we count only those kin who are imprisoned after the birth of ego in order to capture the disruption that the imprisonment of those family members is liable to entail for the average individual living through the event. On the other hand, for measures of prevalence, we count even those kin who were imprisoned before the birth of the focal ego in order to capture the lasting disruption that the imprisonment of those family members may represent for the family network at large.

Finally, we choose to focus on those ever imprisoned-rather than only those currently imprisoned-because the stigma and material costs of the "prison label" do not end with re-entry but often persist for the rest of former prisoners' lives. We recognize the important role of recidivism in concentrating imprisonment risk and prevalence within particularly vulnerable communities. Recent evidence, for instance, suggests that the vast majority of those who go to prison are likely to be rearrested within five years of release (Durose, Cooper, and Snyder 2014). Unfortunately, available data on prison readmission rates are too sparse for us to use to accurately model recidivism in our simulation. Thus, for the purposes of this study, we have elected to remain agnostic about readmission patterns (assuming, in effect, that readmission risk is distributed uniformly across the population regardless of past imprisonment history). Accordingly, our analyses and conclusions do not speak directly to outcomes in which recidivism patterns are of critical importance (such as current imprisonment status). However, not explicitly modeling recidivism in our simulation means we risk overestimating the true prevalence of kin imprisonment (via inflation of prison admission rates due to high rearrest). In order to mitigate this effect, we (1) use data on first admissions whenever possible and (2) calibrate the simulation model such that it reliably reproduces expected rates of first admission (which necessarily discounts readmissions) at the population level (see Appendix A2 of the online supplement).

Our focus on the family centers on its capacity to be a source of both support and strain for its members. In this vein, we pay particular attention to two vulnerable life course periods. First, we examine the incidence and prevalence of imprisonment of same- and older-generation kin during childhood. Second, we describe the incidence and prevalence of imprisonment of younger-generation kin during the post-retirement years. In both cases, we pay special attention to kin who are in their prime working ages (25-54 years old) and thus likely to be an important source of material support for family members.

Because of the historically exceptional nature of mass imprisonment and the stark racial disparities of its reach, we produce estimates of kin imprisonment separately for black and white Americans across two birth cohorts: those born in the period of 1960 to 1970 and those born in the period of 1985 to 1995. These cohorts, spaced 25 years apart, are chosen to represent those most directly impacted by the 
start of the prison boom - those reaching adulthood as mass imprisonment began to ramp up in the '80s and the '90s (the "boom" generation) - and those who would become the second generation living under the peak of that carceral movement (the "post-boom" generation).

In 2015 (the calendar year in which this study was initiated), those born in 1960 and 1985 turned 54 and 29, respectively. In order to provide some sense of how the lifetime experiences of kin imprisonment are likely to differ across generations, we draw out our plots to age 80 for both birth cohorts, assuming that the latest known demographic rate schedules hold constant for unobserved future years. ${ }^{10}$ As a supplementary analysis, we examine three possible future trajectories of imprisonment in the United States: (1) imprisonment rates drop by 75 percent by 2035 (roughly to pre-1980, or pre-prison boom, levels), (2) they drop by 25 percent by 2035 , and (3) they hold steady at the latest known levels.

The first of these scenarios represents a future wherein political initiatives to reduce incarceration in the United States (e.g., the "Cut 50" campaign organized by the Dream Corps; for additional details, see https: / www.cut50.org/) are successful, the second is a future in which such efforts are partially successful, and the third is a future in which the national trend in imprisonment does not change. To characterize the family network consequences of each of these potential futures, we measure the prevalence of kin imprisonment for the 1985-to-1995 post-boom cohort.

Finally, we conduct an exploratory analysis of variation in these estimates by educational attainment (see Appendix A4 of the online supplement). Education, understood as a proxy for class, has been central to previous analyses of prison and the life course (Western and Wildeman 2009). Those with less education consistently face higher risk of imprisonment. Given correlations in educational attainment within families (Ermisch and Pronzato 2010), some kin networks likely face considerably smaller or larger risk and prevalence of kin imprisonment.

\section{Results}

\section{The Risk of Kin Imprisonment}

To characterize the likelihood that an individual experiences the imprisonment of different types of kin over the course of his or her life, we plot age-specific probabilities of first imprisonment ${ }^{11}$ of these kin (contingent on ego surviving to each age ${ }^{12}$ ). To examine how these patterns differ by race and cohort, we draw separate plots for the black and white populations and for the boom (1960-1970) and post-boom (1985-1995) cohorts (Figure 1).

There are three aspects of Figure 1 that we wish to highlight. First, there are clear differences of magnitude in the black and white experiences of kin imprisonment. Averaging across all ages, in both cohorts, a black individual faces a risk of first kin imprisonment per year that is well over three times higher than that of a white individual. At the age of widest racial divergence (age 49 for the boom cohort and age 6 for the post-boom cohort), the average white individual faces a kin imprisonment risk of about 1 imprisonment per every 100 relatives, whereas the average black individual faces a risk of about 1 imprisonment per every 10 relatives. 

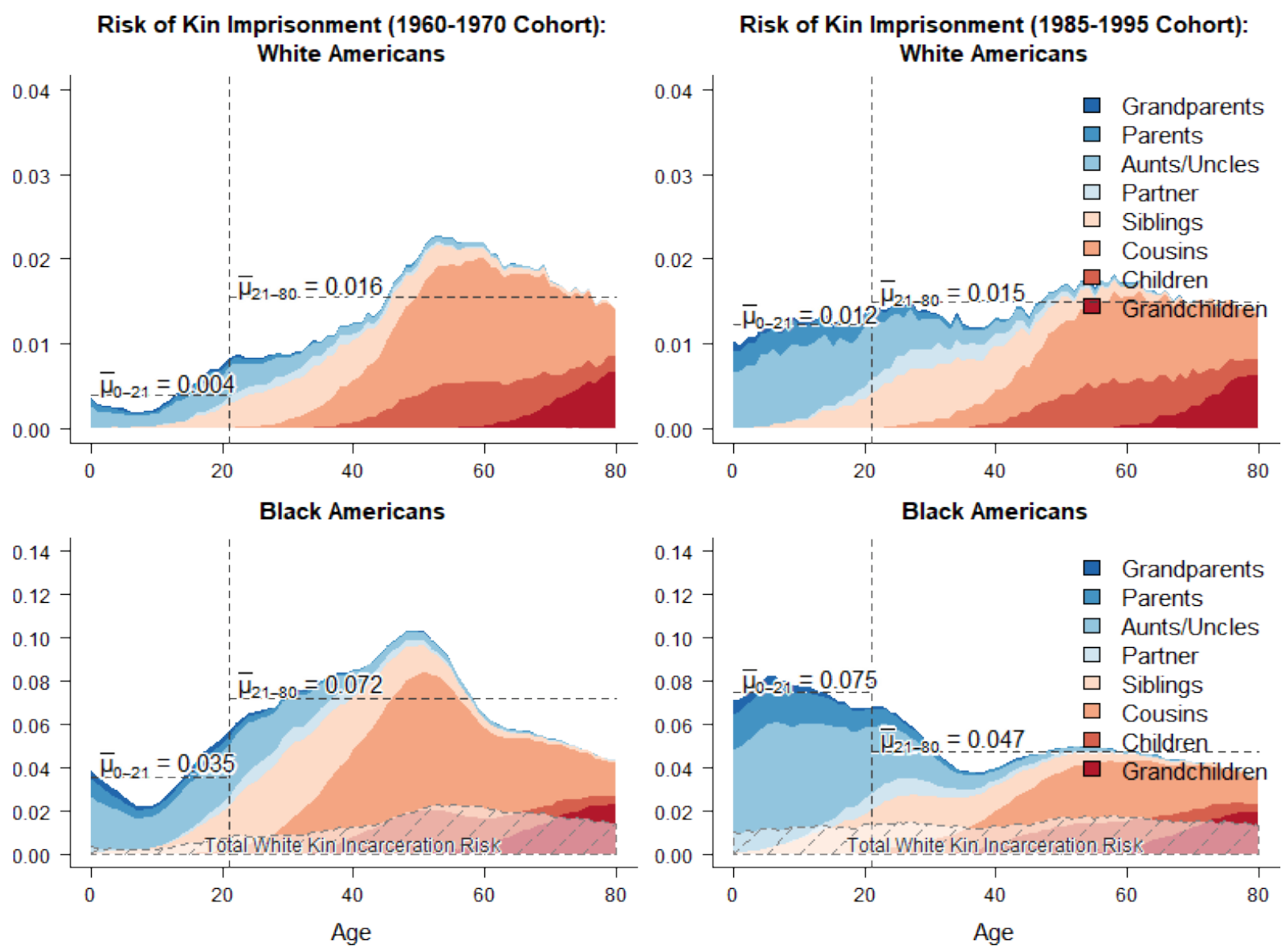

Figure 1: Cohort-specific probabilities of first kin incarceration over age (by relation). The top plots illustrate the contributions of each kin relation to the overall risk profile for white individuals; the bottom plots illustrate the same for black individuals. Horizontal dashed lines indicate mean overall risk before and after age 21 (which is indicated with the vertical dashed line). The total risk density of the white population is superimposed on the bottom (black population) plots to aid comparison across the two different y axis scales.

Second, the proportional distribution of kin-specific risk varies by cohort but relatively little by race. Figure 1 disaggregates each cohort- and race-specific risk curve into its kin-specific components. Within cohorts, we see that though the magnitudes of risk differ quite dramatically between the black and white populations, the relative risks contributed by each kin relation are similar. We see that the relative contribution of older generations (grandparents, parents, and aunts/uncles) to the overall kin imprisonment risk increases over cohorts, whereas the relative contribution of same- or younger-generation kin (partners, siblings, cousins, children, and grandchildren) decreases. This shift reflects two demographic trends: (1) declining birth rates, which reduces the number of siblings and cousins subject to the risk of imprisonment, and (2) declining mortality rates at older ages, which increases the number of grandparents, parents, and aunts/uncles subject 
to the risk of imprisonment. For the white population, this translates to a 15.7 percent reduction in the contribution by same- or younger-generation kin and a corresponding increase in the contribution by older-generation kin to the lifetime risk of kin imprisonment. For the black population, the change in contribution by kin generation is 19.2 percent.

Third, there is a difference in the timing of first kin imprisonment between the two cohorts. The boom cohort tends to experience the first imprisonment of kin later in life than the post-boom cohort. This conforms to expectations given that the mass imprisonment movement reached its peak in the '80s and the '90s, when the boom cohort was just reaching adulthood and the post-boom cohort was just beginning to be born. The average black and white individuals in the boom cohort experience their first kin imprisonment events at ages 17 and 54, respectively. Their counterparts in the post-boom cohort experience this event at ages 7 and 39, respectively. Especially for the black population, this represents a qualitative change in the expected life course; first kin imprisonment is expected to occur during the earliest years of primary school rather than in the years immediately preceding adulthood.

The second and third points highlight the importance of looking at full kin networks. If we were to constrain our focus to just immediate family membersparents, partners, and children-the mean age of experiencing imprisonment of kin for the first time would be 52 for blacks in the boom cohort and 37 for blacks in the post-boom cohort. ${ }^{13}$ This is 30 to 35 years later than the estimates that we provide above. Taking seriously the claim that the imprisonment of family members represents a disruption to normative life course expectations, these earlier observed ages of first kin imprisonment are likely to herald important developmental consequences for families and their most vulnerable members.

\section{The Prevalence of Kin Imprisonment}

Imprisonment signals a state change, not just a momentary disruption. To characterize the prevalence of prisoners and ex-prisoners in the kinship networks of black and white individuals, we plot the proportion of living relatives who have ever been imprisoned at each age of ego (Figure 2).

The age-specific prevalence of imprisonment within kinship networks is generally similar across races: a steady increase over ages. ${ }^{14}$ However, the increasing magnitude of difference between the prevalence of imprisoned members in black kinship networks versus white kinship networks is striking. Within the 1960-to-1970 cohort, 4.2 percent of living black relatives have ever been imprisoned by the time ego reaches age 21 , whereas a roughly similar percentage ( 2.3 percent) of white relatives have ever been imprisoned by the same age. Within the 1985-to-1995 cohort, however, the race difference intensifies: by age 21, 9.4 percent of black relatives have ever been imprisoned, whereas 2.0 percent of white relatives have ever been imprisoned. At age 65, 15.2 percent of black relatives and 3.6 percent of white relatives in the earlier boom cohort have ever been imprisoned; the equivalent figures are 15.3 percent and 5.2 percent in the post-boom cohort. 

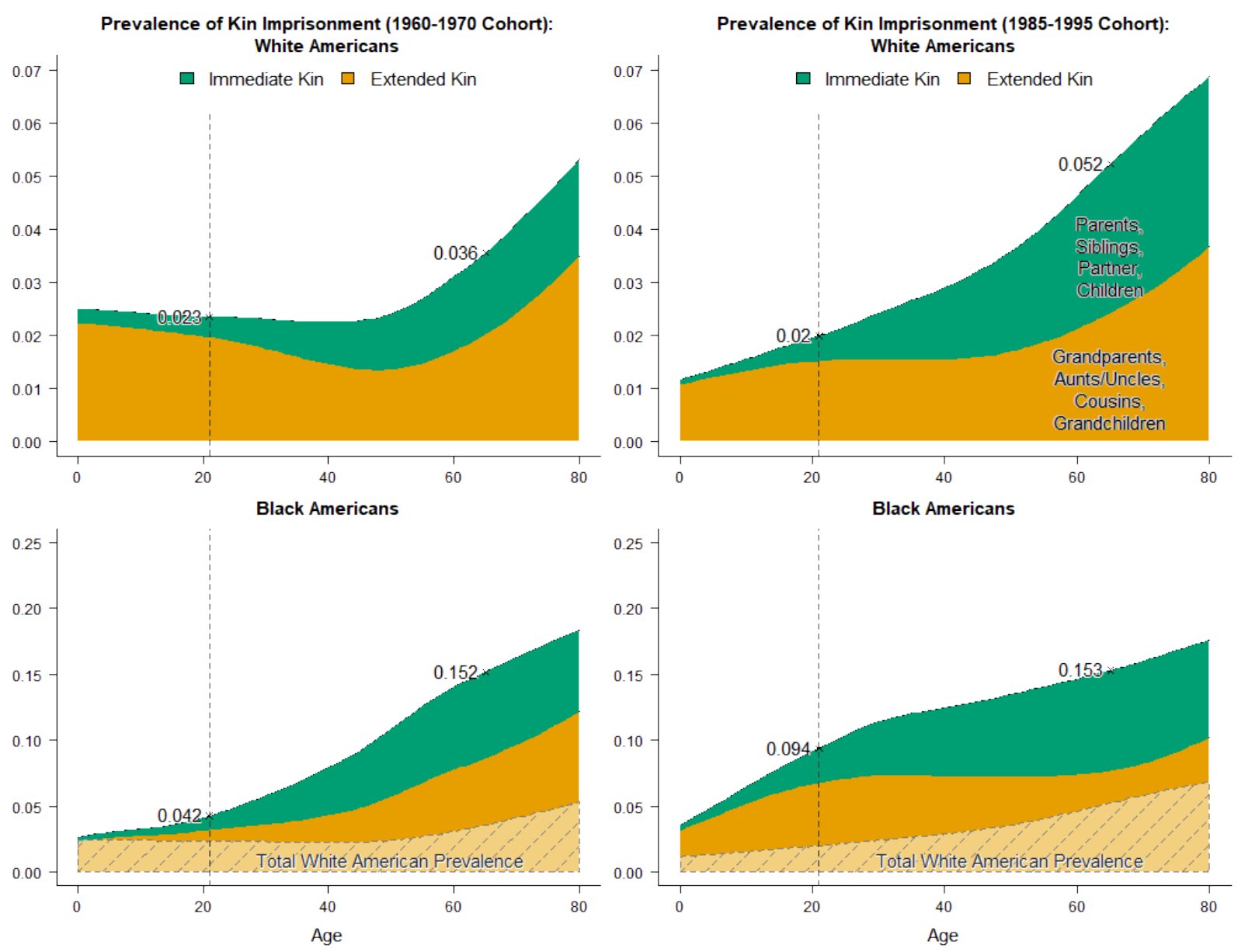

Figure 2: Cohort-specific prevalence of incarceration within kinship networks over age (by relation). The top plots illustrate the proportion of living kin who have ever been incarcerated for white individuals, whereas the bottom plots illustrate the same for black individuals. Points marked by x's indicate the proportion of kin ever incarcerated when ego is age 21 and 65. The total prevalence of incarcerated kin in the white population is superimposed on the bottom (black population) plots to aid comparison across the two different y axis scales.

Although the prevalence of current and former imprisonment within full kinship networks provides useful information regarding the opportunities (or lack thereof) for support in those networks, the large variation in the ages of relatives potentially confounds the true capacity of the kin network to provide that support. We get better purchase on this issue if we examine the prevalence of imprisonment among kin who are of prime working age (Figure 3 ).

When we look exclusively at those relatives of working age (versus all relatives), we see that the proportion ever imprisoned increases at earlier ages. For example, in the boom cohort, 11.1 percent of black working-age relatives have ever been imprisoned by the time ego reaches age 21 compared with 4.2 percent of all relatives.

Table 1 summarizes the findings on the prevalence of kin imprisonment, splitting by cohort, race, and kin type (all kin and working-age kin). 

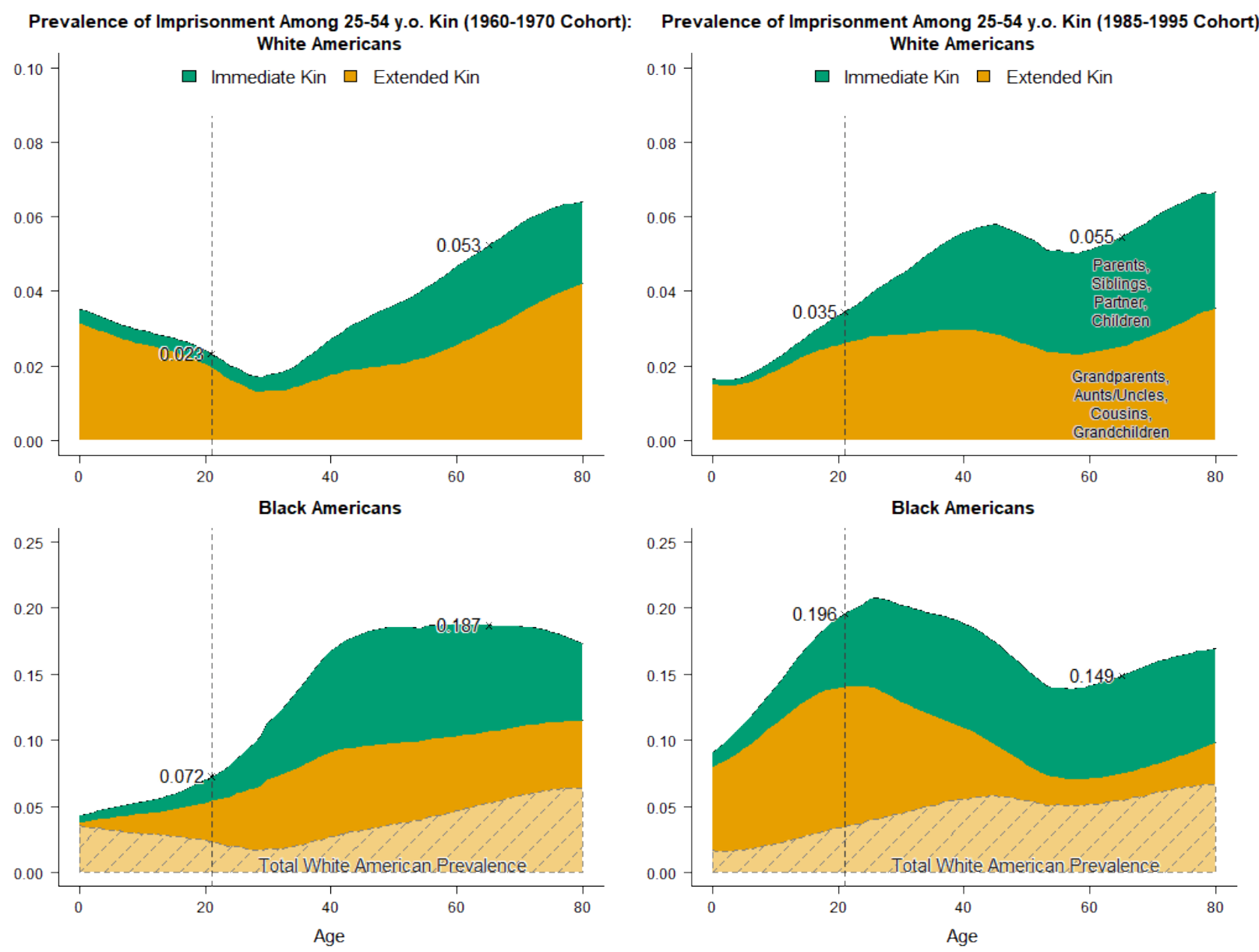

Figure 3: Cohort-specific prevalence of incarceration within kinship networks over age (by relation) among kin who are of working age (25-54 years old). The top plots illustrate the proportion of living kin who have ever been incarcerated for white individuals, whereas the bottom plots illustrate the same for black individuals. Points marked by x's indicate the proportion of kin ever incarcerated when ego is age 21 and 65. The total prevalence of incarcerated kin in the white population is superimposed on the bottom (black population) plots to aid comparison across the two different y axis scales.

Finally, in Figure 4, we resituate the information presented in Figure 3 within the context of full kinship networks. This allows us to illustrate the total "availability" of kin who are hypothetically least constrained in their ability to provide material support for their relatives: those of working age who do not have a prison record.

The proportions of all kin who are of working age and who have ever been imprisoned are substantially higher in black kinship networks. If all imprisonment histories were eliminated from all kinship networks, black individuals in the boom and post-boom cohorts would stand to gain 16.7 percent and 19.2 percent, respectively, in the lifetime prevalence of working-age kin without a prison record. In comparison, the average white individual would stand to gain 4.0 percent and 4.8 percent, respectively. When we translate these proportions into kin-years "lost" to imprisonment, the comparison becomes much more tangible: over the course 
Table 1: Prevalence (in percents) of kin imprisonment by age, race, and type of kin for two cohorts.

\begin{tabular}{|c|c|c|c|c|c|c|c|}
\hline \multicolumn{8}{|c|}{ 1960-1970 Cohort } \\
\hline & & 0 & 5 & 10 & 21 & 65 & 75 \\
\hline \multirow[t]{2}{*}{ White } & all kin & 2.5 & 2.5 & 2.4 & 2.3 & 3.6 & 4.7 \\
\hline & working-age kin & 3.5 & 3.2 & 3.0 & 2.3 & 5.3 & 6.3 \\
\hline \multirow[t]{2}{*}{ Black } & all kin & 2.5 & 3.0 & 3.2 & 4.2 & 15.2 & 17.4 \\
\hline & working-age kin & 4.3 & 4.9 & 5.3 & 11.1 & 15.9 & 15.2 \\
\hline \multicolumn{8}{|c|}{ 1985-1995 Cohort } \\
\hline & & 0 & 5 & 10 & 21 & 65 & 75 \\
\hline \multirow[t]{2}{*}{ White } & all kin & 1.2 & 1.3 & 1.5 & 2.0 & 5.2 & 6.4 \\
\hline & working-age kin & 1.6 & 1.7 & 2.2 & 3.5 & 5.5 & 6.4 \\
\hline \multirow[t]{2}{*}{ Black } & all kin & 3.6 & 5.0 & 6.5 & 9.4 & 15.3 & 16.8 \\
\hline & working-age kin & 9.1 & 11.2 & 14.0 & 19.6 & 14.9 & 16.5 \\
\hline
\end{tabular}

of life, black individuals in the boom and post-boom cohorts lose 90.1 and 83.3 person-years. White individuals lose 20.4 and 19.1 person-years, respectively.

We want to highlight two major findings here. First, for both the black and white populations, a greater proportion of the total kin imprisonment prevalence is due to the imprisonment of extended kin rather than immediate kin. Over the course of life, more than half of all currently and formerly imprisoned relatives in both black and white kinship networks are relatives of the sort that are typically unexamined in studies of the collateral consequences of imprisonment. Second, imprisonment reduces the lifetime availability of never-imprisoned working-age kin for blacks much more dramatically than it does for whites. Furthermore, this "deflation" comes at the heavy cost of increased prevalence of imprisonment among black working-age relatives, converting potential fonts of kin support into sources of kin strain.

\section{Future Trajectories of Kin Imprisonment}

In order to assess the consequences of different possible trajectories of imprisonment in the United States, we plot the prevalence of kin imprisonment for the post-boom (1985-1995) cohort under three scenarios: (1) no change in prison admission rates, (2) a linear 25 percent reduction in prison admission rates by the year 2035, and (3) a linear 75 percent reduction in prison admission rates by the year 2035. Because these future scenarios start in the year 2015, we start our plot at age 20, when the youngest members of the post-boom cohort enter the year 2015 (Figure 5).

As expected, we see that the greater the reduction in future rates of prison admission, the lower the lifetime prevalence of ever-imprisoned kin within family networks. This holds true for both black and white simulated populations. Overall, a 25 percent reduction in prison admission rates by the year 2035 leads to a 16 percent to 23 percent reduction in the proportion of family members ever incarcerated 

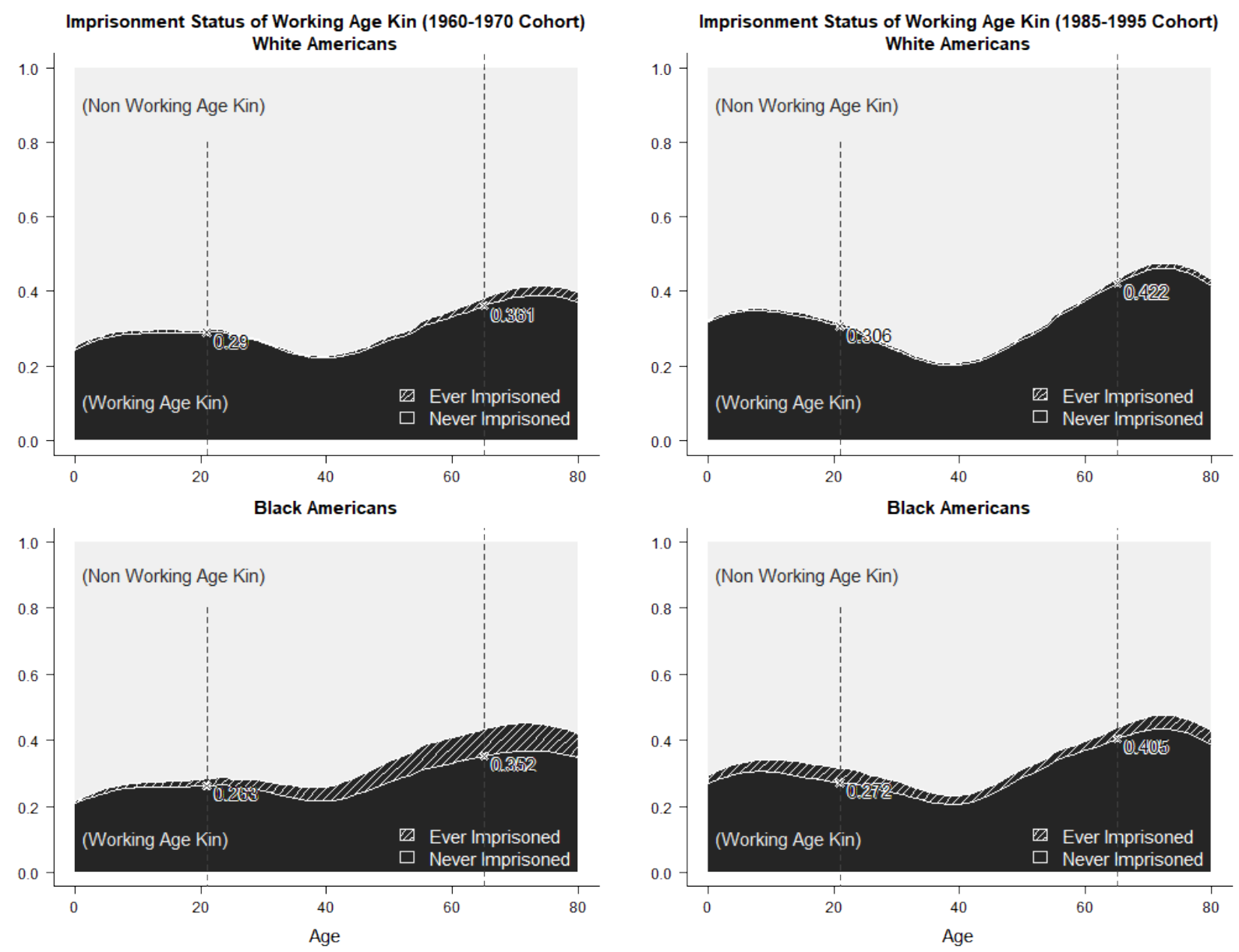

Figure 4: Cohort-specific availability of never-incarcerated, working age (25-54 years old) kin. The top plots illustrate the proportions of working-age kin for white individuals, whereas the bottom plots illustrate the same for black individuals. The shaded regions indicate the share of working-age kin who have ever been incarcerated. Points marked by x's indicate the proportion of kin who are working age and have never been incarcerated when ego is age 21 and 65.

by age 65 , and a 75 percent reduction in prison admission rates leads to a 35 percent to 44 percent reduction in the proportion of family members ever incarcerated by that same age. Though the relative drop in the proportion ever incarcerated is roughly similar across race groups, the absolute drop in these numbers is much more dramatic for blacks than for whites: 15 percent of black family members are expected to have ever been imprisoned by the time ego reaches retirement age under the "No Change" scenario versus 10 percent under the "75 Percent Reduction" scenario. For the white population, the equivalent drop in kin imprisonment prevalence is from 5 percent to 3 percent. The net result of these reductions is a meaningful narrowing of the race disparity in lifetime kin imprisonment prevalence from around 10 percent to 7 percent. That said, it is remarkable that even a 75 percent reduction in future imprisonment rates for the black population would still not 


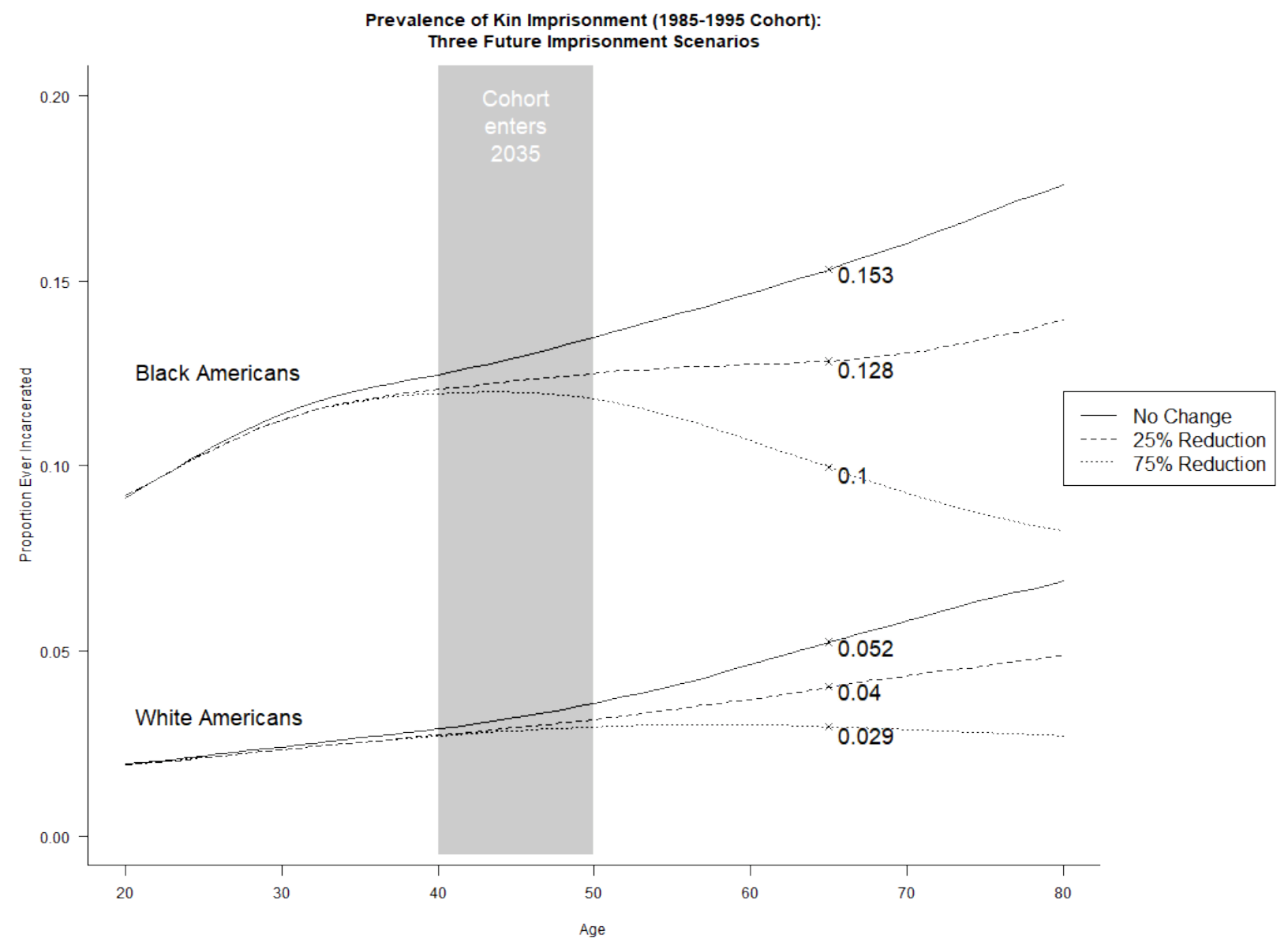

Figure 5: Prevalence of imprisonment within kinship networks over age for the 1985-1995 cohort under three future imprisonment rate scenarios (stratified by race). Dashed and dotted lines are results from simulations in which future imprisonment rates are reduced 25 percent and 75 percent, respectively, by the year 2035. Points marked by x's indicate the proportion of kin ever imprisoned when ego is age 65 .

be enough to bring them to parity with a white population, whose imprisonment rates did not change at all.

Two additional features of these results are worth addressing. First, the " 25 Percent Reduction" scenario sees a net reduction in kin imprisonment prevalence over all ages (compared to the "No Change" scenario), but the prevalence of kin imprisonment still increases monotonically over ages such that the older one gets, the more of one's living relatives are likely to have ever been imprisoned. Under the "75 Percent Reduction" scenario, however, the age trend in kin imprisonment hits an inflection point and begins to decline in mid-to-late adulthood. In other words, there appears to be a particular imprisonment rate threshold beyond which the life course experience of kin imprisonment takes on a qualitatively different character: one eventually reaches a point in life when the older one gets, the fewer of one's living relatives are likely to have ever been imprisoned. 
The second point worth noting is that future reductions in the rate of imprisonment are likely to have a delayed impact on the families of those whose lives have already been touched by the prison boom. For our post-boom (1985-1995) cohort, for example, even a dramatic 75 percent drop in prison rates over a relatively brief 20-year period does not visibly affect the prevalence of kin imprisonment until around middle adulthood. By this time, most individuals will have already completed school, started a career, and have finished having children. Thus, much of the potential gains to familial support are muted for these individuals. Instead, those who stand to gain the most from a reduction in future imprisonment rates are the next generations of Americans, for whom the prison boom would then be an object of historical, rather than personal, memory.

\section{Discussion}

The prison boom of the 1980s and the 1990s has left an indelible mark on the American family. As we have shown, both the likelihood of experiencing the imprisonment of a relative as well as the overall exposure to relatives marked by the prison label has expanded tremendously over time. Furthermore, this expansion has overwhelmingly affected black families.

Research on the collateral consequences of imprisonment has characterized the effects that serving time has on the wider networks of family and friends within which prisoners are embedded. The focal egos in these investigations are typically prisoners' children, partners, and parents. One of the key findings of this study is that these immediate kin members make up a minority of imprisoned or formerly imprisoned kin. Across race and cohorts, more than half of all imprisoned or formerly imprisoned relatives are extended kin.

As we argued above, the imprisonment of extended kin matters because (1) extended family members bear some portion of the material and symbolic costs of kin imprisonment and (2) former prisoners are less able to contribute to future kin support. These two factors can interact in ways that undermine norms of reciprocity and trust and ultimately weaken kin networks. These networks have been shown to be particularly important for black families.

We find that those born at the height of the prison boom (1985-1995) are at higher risk of experiencing the first imprisonment event of a same- or older-generation relative during childhood and adolescence than those born 25 years prior. This translates into experiences of kin imprisonment at much earlier ages (up to 15 years earlier) and higher lifetime prevalences of ever-imprisoned relatives within kinship networks when comparing across birth cohorts. These trends signal an alarming growth in the collateral consequences falling on the American family due to the growing carceral state over the past several decades.

Within cohorts, race differences in the experience of kin imprisonment are the most compelling story. White Americans alive at the height of the prison boom are likely to have had very few occasions to deal with the strain, stigma, or trauma of imprisonment. Black Americans over the same period, by contrast, were substantially more likely to have to shoulder that burden for either themselves or their kin, often during their most vulnerable ages. Black individuals (relative to white 
individuals) are at substantially higher risk of experiencing the first imprisonment event of a relative at every age, are likely to experience that event at much earlier ages, and have proportionately more relatives who have ever been imprisoned. At age 6, the moment of widest racial disparity in kin imprisonment risk for the 1985-to-1995 cohort, the average black individual loses 1 of every 10 relatives to imprisonment, whereas the average white individual loses 1 of every 100 .

By age 21, 9.4 percent of black relatives have acquired a prison record versus 2.0 percent of white relatives. This represents a nearly fivefold-higher probability of black individuals having currently or formerly imprisoned relatives within their kinship networks at the moment they first enter their adult years. By age 65, the normative age of retirement, the race difference is even wider: 15.3 percent of black relatives versus 5.2 percent of white relatives with a prison record. Over the course of life, this translates to 83.3 person-years of potential support from working-age relatives lost to imprisonment for black Americans and 19.1 person-years lost for white Americans. By all these measures, the collateral consequences of the growing carceral state appear to be disproportionately borne by black families.

But what about the future? With increasing agreement among researchers, activists, and policymakers that the current carceral system is in need of reform, we are likely to see efforts to reduce the national rate of imprisonment. The results of our analysis suggest that the consequences of such efforts are likely to be profound (especially for black families) but also delayed. For those who lived through the prison boom, the damage, in some sense, has already been done. The prevalence of imprisonment within their families will not see much change even if dramatic cuts to imprisonment rates are implemented quite soon.

However, this does not indicate that efforts to reduce imprisonment are wasted. On the contrary, the importance of such initiatives to the future family lives of our most recent generations is likely to be quite pronounced. What is more, our analysis suggests that there may be a clear benefit to reducing national imprisonment rates as much as possible: below some threshold imprisonment rate, the age trend in the prevalence of imprisonment within kinship networks stops increasing monotonically and instead takes on an inverted-U shape. The implications of such a qualitative shift, from a life course perspective, are enormous. By achieving an imprisonment rate low enough to trigger a midlife decline in familial imprisonment burden, we would enable Americans, for the first time in several decades, to see the reach of the carceral state into their families recede rather than increase over their own lifetimes.

\section{Future Directions}

This article estimates, in broad strokes, how mass imprisonment differentially affects the composition of black and white kin networks. This is in many ways a preliminary analysis. We suggest three major avenues for future research building on these findings.

First, given adequate data, the simulations carried out here could be extended in a number of ways. In Appendix A4 of the online supplement, we provide a first example of how this might be done by incorporating known variations by educa- 
tion in lifetime risk of imprisonment (Pettit and Western 2004). Given race-specific measures of assortative mating, cross-generational educational transmission, and repeated cross-sections of family educational composition, those estimates could be substantially improved. Wildeman and Wakefield's (2014) recent work suggests that the concentration of imprisonment within families also warrants further investigation. Our simulations do not-but with sufficient data potentially could—account for any intergenerational transmission or clustering of imprisonment risk within family networks. Full simulations are plausible but require increasingly sophisticated procedures to ensure the reliability and accuracy of simulated estimates. Confirmation of resulting estimates would also likely require collection of new sorts of network data.

Second, results from these simulations should lead to reassessment of previous findings on the collateral consequences of imprisonment. We agree wholeheartedly with Wildeman and Wakefield in their assessment that "the massive literature considering the effects of parental imprisonment on children may have been picking up not solely a direct effect of parental imprisonment, but a combined effect of parental imprisonment and broader family member imprisonment" (Wildeman and Wakefield 2014:389). Much the same could be said about research on the effects of imprisonment on romantic partners and mothers of prisoners. If others in the ego's kin network are also imprisoned and straining either ego's or the network's resources, then the direct effect of proximate-kin imprisonment may be overestimated.

Finally, third, we believe there is more to be gleaned from analyzing the extended family as a meso-level institution. For example, the results presented here have implications for reintegration of former prisoners. Families are the primary social institutions to which the formerly imprisoned return (Harding et al. 2014). Our study draws attention to the changing composition of these families across race and over time. Different types of kin networks may be more or less supportive of the reintegration process. Does having higher proportions of relatives in their prime working ages mean that more material support is available to re-entrants? Is this effect tempered if that group has a large percentage of ex-prisoners?

As another example, black-white differences in kin imprisonment may have a direct effect on the racial wealth gap (Braman 2004). Research suggests that ties to poor and less educated kin serve as an obstacle to individual financial wellbeing and wealth accumulation; differentials in incidence of such ties serve to explain a portion of the racial wealth gap (Heflin and Pattillo 2002, 2006; O'Brien 2012). The effects of ties to prisoners and ex-prisoners-alters who make significant, unreciprocated demands on ego's resources-may be even more severe. Turney and Schneider (2016) provide initial support for this claim, demonstrating that imprisonment lowers odds of romantic partner asset ownership. Such spillover effects, when evaluated at the network level and across the racial divide, may prove significant.

\section{Strengths and Limitations}

The results presented here are based on data constructed by using a microsimulation strategy. Consequently, we conduct our analyses with data that is demographically 
complete and longitudinal for all individuals in our (simulated) populations of interest. This allows for the exact measurement of genealogical relatedness and the ability to track those genealogical linkages over both individual and historical time. We are able to explore the kinship configurations of the imprisoned population with an unprecedented level of detail. These data take into account female imprisonment and-via our exploratory analyses with education rates-class variation in imprisonment rates.

This study also suffers from a number of limitations. Some of these are inherent in the nature of simulated data. The kinship networks that we develop and describe above are not "real" (in the sense that they are not derived from measurements of real people). In other words, we observe only the structures, not the cultural patterns that underlie or result from them. And the consequences of these structures are largely hypothetical. We attempt to justify the hypotheses, but these data do not allow us to test them directly.

Other problems are related to data availability and our choices in the configuration of SOCSIM, our microsimulator. In an effort to streamline our process, we have omitted several factors that may be of importance. First, we do not account for the significant geographic variation in imprisonment rates (Muller and Wildeman 2016; Wakefield and Uggen 2010). The rates we use are nationwide averages; lived experiences will be shaped depending on whether an individual (and the kin network) resides in a more or less punitive state. We also do not account for intrafamilial correlations in risk of imprisonment except via the education simulation. Our simulations also rely on an assumption of strict racial homogamy. Such an assumption is fairly well warranted given historical American marital patterns but may be less tenable moving forward.

Finally, our simulations provide estimates only for the risk and prevalence of imprisonment (prison incarceration) within kin networks. There is a class of individuals who experience jail incarceration but not imprisonment. These individualsespecially those charged with felonies-are subject to similar social sanctions, and their families may bear burdens equivalent to those associated with kin imprisonment (Comfort 2016). Our estimates do not capture the experience of such families and thus necessarily underestimate the full reach of the carceral system into kin networks.

\section{Conclusion}

Understanding the collateral consequences of mass imprisonment and their effects on racial inequalities and stratification processes requires us to fully account for the affected. Meeting this requirement, we argue, is not simply a matter of getting the qualitative story right. Good existing research has already established that the consequences of mass imprisonment spill over into the lives of friends and relatives of the imprisoned and that these collateral consequences fall unevenly according to race and class. What we need, in addition, is a careful identification of the scale at which we assess our outcomes. Cast the net too narrowly and we are liable to mischaracterize the consequences of the modern carceral system by underestimating the likely exposure of individuals to those consequences. To wit, 
existing research has suggested the ways in which imprisonment affects the life chances of prisoners' most immediate family members: the children, partners, and, on occasion, parents of the imprisoned. However, our present work suggests that we may be missing more than half the story of familial imprisonment if we fail to account for the connectedness of extended kin.

\section{Notes}

1 Our focus is on prison rather than jail incarceration. As such, we use the term "imprisonment" throughout this article in reference to only this particular type of incarceration.

2 A number of reviews provide insightful summaries of the literature on collateral consequences of imprisonment for families. See Comfort (2007); Kirk and Wakefield (2018); Wakefield, Lee, and Wildeman (2016); Wakefield and Uggen (2010); and Wildeman and Muller (2012).

3 Lee et al. (2014) represents an exception; Braman (2004) provides a standout example of qualitative work on consequences beyond the immediate family.

4 We choose to look at non-Hispanic populations primarily due to inconsistent reporting of ethnicity over the period of interest.

5 Additional information on SOCSIM may be found in Hammel and Wachter (1976); Wachter, Blackwell, and Hammel (1997); and online at http:/ /lab.demog.berkeley.edu/socsim.

6 Averaging results across 25 replicate simulations effectively reduces the stochastic error of our estimates to zero.

7 Appendix Table A1-2 of the online supplement provides a summary of how these interpolated year-specific distributions of age, race, and sex are assigned to each simulated year of admission and release count data.

8 What is thus assumed by our calibration method is confidence in the general shapes of the age-specific mortality, fertility, prison admission, and prison release curves that we input but uncertainty regarding their exact magnitudes. A more technical treatment of the procedure is provided in Appendix A2 of the online supplement.

9 Full details of this validation exercise, including complete comparison tables, is provided in Appendix A3 of the online supplement.

10 Consequently, although the reliability of our kinship estimates for the 1960-to-1970 cohort is likely to be reasonably good across most ages, our estimates for the later ages of the 1985-to-1995 cohort are subject to the uncertainties inherent in projection.

11 By "first imprisonment," we simply mean the first time a unique member of ego's kinship network is imprisoned. This represents the transition from never- to ever-imprisoned status.

12 If kin imprisonment events occur prior to the birth or following the death of an individual, those kin imprisonment events are not observed for that individual and thus not counted as part of the numerator. Kin imprisonment that occurs before ego's birth does factor into the prevalence calculations in the subsequent sections.

13 The mean age of first kin imprisonment for whites for this reduced set of kin relations (i.e., the age at which the cumulative sum of annual risk tips past 50 percent) shoots off the charts well into the postcentenarian years.

14 In the case of white Americans born between 1960 and 1970, the prevalence remains largely stable until about age 50, when it begins its upward movement. 


\section{References}

Ajrouch, Kristine J., Toni C. Antonucci, and Mary R. Janevic. 2001. "Social Networks among Blacks and White: The Interaction between Race and Age." Journals of Gerontology Series B: Psychological Sciences and Social Sciences 56B:S112-6. https://doi .org/10.1093/geronb/ 56.2.S112.

Arias, Elizabeth. 2014. “United States Life Tables, 2010." National Vital Statistics Reports 62:1-63.

Bonczar, Thomas P. 2003. Prevalence of Imprisonment in the U.S. Population, 1974-2001. Washington, DC: Bureau of Justice Statistics.

Bonczar, Thomas P., and Allen J. Beck. 1997. Lifetime Likelihood of Going to State or Federal Prison. Washington, DC: Bureau of Justice Statistics.

Braman, Donald. 2004. Doing Time on the Outside: Incarceration and Family Life in Urban America. Ann Arbor, MI: University of Michigan Press. https ://doi .org/10.3998/mpub . 17629.

Carson, E. Ann, and Daniela Golinelli. 2013. Prisoners in 2012. Washington, DC: Bureau of Justice Statistics.

Carson, E. Ann, and William J. Sabol. 2014. Prisoners in 2013. Washington, DC: Bureau of Justice Statistics.

Clear, Toff R. 2007. Imprisoning Communities: How Mass Incarceration Makes Disadvantaged Neighborhoods Worse. New York, NY: Oxford University Press. https://doi.org/10. 1093/acprof : oso/9780195305791.001.0001.

Comfort, Megan. 2007. "Punishment beyond the Legal Offender." Annual Review of Law and Social Science 3:271-96. https ://doi .org/10.1146/annurev . lawsocsci.3.081806. 112829.

Comfort, Megan. 2016. “'A Twenty-Hour-a-Day Job': The Impact of Frequent Low-Level Criminal Justice Involvement on Family Life." Annals of the American Academy of Political and Social Science 665:63-79. https : //doi .org/10.1177/0002716215625038.

de Souza Briggs, Xavier. 1998. "Brown Kids in White Suburbs: Housing Mobility and the Many Faces of Social Capital." Housing Policy Debate 9:177-221. https ://doi .org/10. 1080/10511482.1998.9521290.

DeVuono-Powell, Saneta, Chris Schweidler, Alicia Walters, and Azadeh Zohrabi. 2015. Who Pays? The True Cost of Incarceration on Families. Oakland, CA: Ella Baker Center, Forward Together, Research Action Design.

Durose, Matthew R., Alexia D. Cooper, and Howard N. Snyder. 2014. Recidivism of Prisoners Released in 30 States in 2005: Patterns from 2005 to 2010 - Update. Washington, DC: Bureau of Justice Statistics. Retrieved March 17, 2016. http://www.bjs.gov/index.cfm?ty= pbdetail\%7B/\&\%7Diid=4986.

Ermisch, John, and Chiara Pronzato. 2010. Causal Effects of Parents' Education on Children's Education Vol. 16. Colchester, UK: Institute for Social and Economic Research, University of Essex.

Geller, Amanda, Irwin Garfinkel, and Bruce Western. 2011. "Paternal Incarceration and Support for Children in Fragile Families." Demography 48:25-47. https : //doi .org/10. 1007/s13524-010-0009-9.

Geller, Amanda, Kate Jaeger, and Garrett T. Pace. 2016. "Surveys, Records, and the Study of Incarceration in Families." Annals of the American Academy of Political and Social Science 665:22-43. https://doi.org/10.1177/0002716216633449. 
Green, Kerry M., Margaret E. Ensminger, Judith A. Robertson, and Hee-Soon Juon. 2006. “Impact of Adult Sons' Incarceration on African American Mothers' Psychological Distress." Journal of Marriage and Family 68:430-41. https://doi .org/10.1111/j .1741-3737. 2006. $00262 . x$.

Hagan, John, and Holly Foster. 2012. "Children of the American Prison Generation: Student and School Spillover Effects of Incarcerating Mothers." Law and Society Review 46:37-69. https://doi.org/10.1111/j.1540-5893.2012.00472.x.

Hamilton, Brady E., and Candace M. Cosgrove. 2010. Central Birth Rates, by Live-Birth Order, Current Age, and Race of Women in Each Cohort from 1911 through 1991: United States, 1960-2005. Table 1. Hyattsville, MD: National Center for Health Statistics.

Hamilton, Brady E., and Candace M. Cosgrove. 2012. Central Birth Rates, by Live-Birth Order, Current Age, and Race of Women in Each Cohort from 1957 through 1995: United States, 2006-2009. Table 1. Hyattsville, MD: National Center for Health Statistics.

Hammel, Eugene, and Ken Wachter. 1976. The SOCSIM Demographic-Sociological Microsimulation Program: Operating Manual. Berkeley, CA: Institute of International Studies; University of California, Berkeley.

Harding, David J., Jessica J. B. Wyse, Cheyney Dobson, and Jeffrey D. Morenoff. 2014. "Making Ends Meet After Prison." Journal of Policy Analysis and Management 33:440-70. https://doi.org/10.1002/pam. 21741.

Harris, Alexes, Heather Evans, and Katherine Beckett. 2010. "Drawing Blood from Stones: Legal Debt and Social Inequality in the Contemporary United States." American Journal of Sociology 115:1753-99. https: //doi .org/10.1086/651940.

Heflin, Colleen M., and Mary Pattillo. 2002. "Kin Effects on Black-White Account and Home Ownership." Sociological Inquiry 72:220-39. https://doi.org/10.1111/1475-682X. 00014.

Heflin, Colleen M., and Mary Pattillo. 2006. "Poverty in the Family: Race, Siblings, and Socioeconomic Heterogeneity." Social Science Research 35:804-22. https : //doi . org/10 . 1016/j.ssresearch.2004.09.002.

Heuser, Robert L. 1976. Fertility Tables for Birth Cohorts by Color: United States, 1917-73. Rockville, MD: US Department of Health, Education, and Welfare; US Public Health Service, Health Resources and Services Administration, National Center for Health Statistics.

Jayakody, Rukmalie. 1998. "Race Differences in Intergenerational Financial Assistance: The Needs of Children and the Resources of Parents." Journal of Family Issues 19:508-33. https://doi.org/10.1177/019251398019005002.

Johnson, Colleen L., and Barbara M. Barer. 1995. “Childlessness and Kinship Organization: Comparisons of Very Old Whites and Blacks." Journal of Cross-Cultural Gerontology 10:289306. https://doi.org/10.1007/BF00972330.

Keene, Jennifer Reid, and Christie D. Batson. 2010. “Under One Roof: A Review of Research on Intergenerational Coresidence and Multigenerational Households in the United States." Sociology Compass 4:642-57. https: //doi .org/10.1111/j.1751-9020.2010.00306 .x.

Kirk, David, and Sara Wakefield. 2018. "Collateral Consequences of Punishment: A Critical Review and Path Forward." Annual Review of Criminology 1:171-94. https ://doi .org/ 10.1146/annurev-criminol-032317-092045.

Langan, Patrick A. 1991. Race of Prisoners Admitted to State and Federal Institutions, 1926-86 Vol. 97. Collingdale, PA: DIANE Publishing.

Lee, Hedwig, Christopher Wildeman, Emily A. Wang, Niki Matusko, and James S. Jackson. 2014. "A Heavy Burden: The Cardiovascular Health Consequences of Having a Family 
Member Incarcerated." American Journal of Public Health 104:421-7. https : //doi .org/10. 2105/A JPH . 2013. 301504.

Lee, Hedwig, Tyler McCormick, Margaret T. Hicken, and Christopher Wildeman. 2015. "Racial Inequalities in Connectedness to Imprisoned Individuals in the United States." Du Bois Review 12:269-82. https ://doi . org/10.1017/S1742058X15000065.

Lee, Yean-Ju, and Isik A. Aytac. 1998. "Intergenerational Financial Support among Whites, African Americans, and Latinos." Journal of Marriage and the Family 60:426-41. https: //doi.org/10.2307/353859.

Lynch, James P., and William J. Sabol. 2004. "Assessing the Effects of Mass Incarceration on Informal Social Control in Communities." Criminology and Public Policy 3:267-94. https://doi.org/10.1111/j.1745-9133.2004.tb00042.x.

Massoglia, Michael. 2008. "Incarceration as Exposure: The Prison, Infectious Disease, and Other Stress-Related Illnesses." Journal of Health and Social Behavior 49:56-71. https : //doi.org/10.1177/002214650804900105.

Muller, Christopher, and Christopher Wildeman. 2016. "Geographic Variation in the Cumulative Risk of Imprisonment and Parental Imprisonment in the United States." Demography 53:1499-509. https://doi .org/10.1007/s13524-016-0493-7.

Murray, Joseph, and David P. Farrington. 2008. “The Effects of Parental Imprisonment on Children." Crime and Justice 37:133-206. https : //doi .org/10.1086/520070.

Nagrecha, Mitali, Mary F. Katzenstein, and Estelle Davis. 2015. When All Else Fails, Fining the Family: First Person Accounts of Criminal Justice Debt. Syracuse, NY: Center for Community Alternatives.

O’Brien, Rourke L. 2012. “Depleting Capital? Race, Wealth and Informal Financial Assistance." Social Forces 91:375-96. https://doi.org/10.1093/sf/sos132.

Pettit, Becky, and Bruce Western. 2004. "Mass Imprisonment and the Life Course: Race and Class Inequality in U.S. Incarceration." American Sociological Review 69:151-69. https: //doi.org/10.1177/000312240406900201.

Raley, R. Kelly. 1995. “Black-White Differences in Kin Contact and Exchange Among Never Married Adults." Journal of Family Issues 16:77-103. https : //doi .org/10 .1177/ 019251395016001005.

Rose, Dina R., and Todd R. Clear. 2004. “Who Doesn't Know Someone in Jail? The Impact of Exposure to Prison on Attitudes toward Formal and Informal Controls." The Prison Journal 84:228-47. https://doi .org/10.1177/0032885504265079.

Sarkisian, Natalia, and Naomi Gerstel. 2004. "Kin Support among Blacks and Whites: Race and Family Organization." American Sociological Review 69:812-37. https : //doi . org/10 . $1177 / 000312240406900604$.

Schwartz-Soicher, Ofira, Amanda Geller, and Irwin Garfinkel. 2011. "The Effect of Paternal Incarceration on Material Hardship." The Social Service Review 85:447-73. https ://doi . org/10.1086/661925.

Sykes, Bryan L., and Becky Pettit. 2014. "Mass Incarceration, Family Complexity, and the Reproduction of Childhood Disadvantage." Annals of the American Academy of Political and Social Science 654:127-49. https ://doi .org/10.1177/0002716214526345.

Taylor, Robert Joseph, Linda M. Chatters, Amanda Toler Woodward, and Edna Brown. 2013. "Racial and Ethnic Differences in Extended Family, Friendship, Fictive Kin, and Congregational Informal Support Networks." Family Relations 62:609-24. https ://doi . org/10.1111/fare.12030. 
Turney, Kristin. 2014. "The Intergenerational Consequences of Mass Incarceration: Implications for Children's Co-residence and Contact with Grandparents." Social Forces 93:299-327. https://doi.org/10.1093/sf/sou062.

Turney, Kristin, and Daniel Schneider. 2016. "Incarceration and Household Asset Ownership." Demography 53:2075-103. https : //doi .org/10.1007/s13524-016-0519-1.

Uggen, Christopher, Jeff Manza, and Melissa Thompson. 2006. “Citizenship, Democracy, and the Civic Reintegration of Criminal Offenders." The Annals of the American Academy of Political and Social Science 605:281-310. https: //doi .org/10.1177/0002716206286898.

United States Bureau of Justice Statistics. 2016a. National Corrections Reporting Program, 1991-2014: Selected Variables (ICPSR 36404). Ann Arbor, MI: Inter-university Consortium for Political and Social Research. Retrieved March 15, 2016. http://www . icpsr . umich . edu/icpsrweb/NACJD/series/38/studies/36404.

United States Bureau of Justice Statistics. 2016b. Survey of Inmates in State and Federal Correctional Facilities: 1974, 1979, 1986, 1991, 1997, 2004. Ann Arbor, MI: Inter-university Consortium for Political and Social Research. Retrieved March 15, 2016. http://www . icpsr. umich. edu/icpsrweb/NACJD/series/70.

United States Census Bureau. 2015. Population Estimates: Historical and Intercensal Estimates, 1900-2012. Washington, DC: United States Census Bureau Population Division.

University at Albany, Hindelang Criminal Justice Research Center. 2012. "Number and Rate (per 100,000 Resident Population in Each Group) of Sentenced Prisoners under Jurisdiction of State and Federal Correctional Authorities on December 31 (Table 6.28.2012)." Sourcebook of Criminal Justice. Retrieved March 16, 2016. https: //www. albany. edu/sourcebook/pdf/t6282012.pdf.

Wachter, Kenneth W., Debra Blackwell, and Eugene A. Hammel. 1997. "Testing the Validity of Kinship Microsimulation." Mathematical and Computer Modelling 26:89-104. https : //doi.org/10.1016/S0895-7177(97)00172-6.

Wakefield, Sara, and Christopher Uggen. 2010. "Incarceration and Stratification." Annual Review of Sociology 36:387-406. https : //doi .org/10.1146/annurev . soc . 012809. 102551.

Wakefield, Sara, and Christopher Wildeman. 2014. Children of the Prison Boom: Mass Incarceration and the Future of American Inequality. Oxford, United Kingdom: Oxford University Press.

Wakefield, Sara, Hedwig Lee, and Christopher Wildeman. 2016. "Tough on Crime, Tough on Families? Criminal Justice and Family Life in America." Annals of the American Academy of Political and Social Science 2 665:8-21. https://doi .org/10.1177/0002716216637048.

Western, Bruce, and Christopher Wildeman. 2009. "The Black Family and Mass Incarceration." The Annals of the American Academy of Political and Social Science 621:221-42. https: //doi.org/10.1177/0002716208324850.

Wildeman, Christopher. 2009. "Parental Imprisonment, the Prison Boom, and the Concentration of Childhood Disadvantage." Demography 46:265-80. https ://doi .org/10.1353/ dem.0.0052.

Wildeman, Christopher, and Christopher Muller. 2012. "Mass Imprisonment and Inequality in Health and Family Life." Annual Review of Law and Social Science 8:11-30. https: //doi.org/10.1146/annurev-lawsocsci-102510-105459.

Wildeman, Christopher, Jason Schnittker, and Kristin Turney. 2012. “Despair by Association? The Mental Health of Mothers with Children by Recently Incarcerated Fathers." American Sociological Review 77:216-43. https://doi .org/10.1177/0003122411436234. 
Wildeman, Christopher, and Kristin Turney. 2014. "Positive, Negative, or Null? The Effects of Maternal Incarceration on Children's Behavioral Problems." Demography 51:1041-68. https://doi.org/10.1007/s13524-014-0291-z.

Wildeman, Christopher, and Sara Wakefield. 2014. "The Long Arm of the Law: The Concentration of Incarceration in Families in the Era of Mass Incarceration." Journal of Gender, Race and Justice 17:367-89.

Acknowledgements: We gratefully acknowledge David Harding, Kristin Turney, Sandra Susan Smith, Daniel Schneider, Christopher Wildeman, Robert Pickett, and Elayne Oliphant for the invaluable advice and feedback they provided at various stages of this work.

Pil H. Chung: Departments of Sociology and Demography, University of California, Berkeley. E-mail: pchung@berkeley.edu.

Peter Hepburn: Departments of Sociology and Demography, University of California, Berkeley. E-mail: pshepburn@demog.berkeley.edu. 